\title{
Estrelas de Letras. Teatralidades do poema no Brasil pós-1970 ${ }^{1}$
}

Resumo: Por meio da leitura de poemas de Paulo Leminski, Ana Cristina Cesar e Veronica Stigger, o ensaio aborda uma noção do teatro da poesia apta a iluminar um estatuto paradoxal e múltiplo do espaço do poema, visto pelos olhos da produção brasileira a partir da década de 1970. Para tanto, explora alguns agenciamentos contemporâneos de um campo teórico e prático antiteatral oriundo de contextos modernos, onde poesia, teatro e artes visuais convergem em encenações plurais do problema da especificidade.

Palavras-chave: poesia contemporânea, teatralidade, transmedialidade

Abstract: By analyzing poems by Paulo Leminski, Ana Cristina Cesar and Veronica Stigger, this essay puts forward a notion of the theater of poetry aiming at clarifying a paradoxal and multiple status of the space of the poem, seen through de lenses of Brazilian poetry produced from de 1970s on. For doing so, it approaches a few contemporary modes of reception of a theoretical and practical antitheatrical field inherited from a modern context, where poetry, theater and visual arts hold converge by means of plural mises-en-scène of the specifity problem.

Keywords: contemporary poetry, theatricality, transmediality 
REDE INTERNACIONAL LYRACOMPOETICS

André Goldfeder

\begin{abstract}
não sou o silêncio
que quer dizer palavras

ou bater palmas

pras performances do acaso

sou um rio de palavras

peço um minuto de silêncios

pausas valsas calmas penadas

e um pouco de esquecimento

apenas um e eu posso deixar o espaço

e estrelar este teatro

que se chama tempo
\end{abstract}

(Leminski 2013: 39)

Nesse singelo poema de Paulo Leminski, a poesia atravessa uma multiplicidade que se insinua entre o mínimo e o máximo, para encenar-se como conquista do teatro. De início, o que entra em cena pode refletir a trajetória individual relatada pelo poeta dois anos após a publicação de Caprichos \& relaxos (1983): “Durante muito tempo, escrevi no espaço, no espaço branco da página, a página do livro, da revista, a página do pôster. Agora eu poeto no tempo, na substância fugaz da voz, na música, na cadeia de sons da vida" (Leminski apud Aleixo 2004: 290-91). Porém, impressa nessa trajetória individual entra em cena toda a carga artística e histórica impressa na "cisma" que dividiu o campo da poesia brasileira das décadas de 1960 e 1970, entre "experiência e experimentação" (Siscar 2011), entre "relaxo e capricho" ou as vias da "poesia dita 'engajada' ou 'participante"” e a das “"vanguardas”, como coloca o próprio autor (Leminski 2012: 60). De modo que, se Leminski conquista um oblíquo caminho do meio diante dessa alternativa, tal caminho passará por um reagenciamento da herança concretista a partir de um "lugar de enunciação paradoxal", que "difere o lugar da voz e aciona diferentes planos enunciativos" (Zular; Lucas 2016). ${ }^{2}$ Algo que se pode apresentar passando do contraste entre antes e "agora" à compreensão do regime de simultaneidade múltipla posto em ato no espaço-tempo aberto do livro.

Ao mesmo tempo, em se tratando de poema que encena o próprio encenar, vale tomá-lo com convite para olhar de perto essa palavra, "encenação", que tanto rende como metáfora crítica para a escrita de poesia. O que significaria encontrar nela, para além do metafórico, alguns funcionamentos poemáticos que podem operar nessa chave, bem como certos trânsitos que se projetam da poesia ao o teatro e vice-versa. Seria o caso, nesse sentido, de seguir a trilha de uma noção possível de teatro, pensado como espaço de encenação de tensões e paradoxos entre a materialidade e a imaterialidade do poema, o pensamento e o ato, o dizer e o mostrar, o espacial e o temporal, o aural e o 
escópico. Em poucas palavras, trata-se de explorar um vocabulário conceitual de ordem teatral para pensar o poema como mínima "obra de arte total”, mediante uma reversão radical da noção de totalidade e deixando de lado o horizonte essencialista e autoritário que marca o sentido original da fórmula wagneriana, em direção a outros desdobramentos dessas relações postas em regime de decomposição, que permanecerão ocupando o palco.

\section{Para estrelar o teatro do poema}

Entremos no poema. A primeira estrofe impressiona em sua capacidade de pôr em jogo oposições densas de memória e amplitude e, simultaneamente, seus desdobramentos paradoxais. O sujeito está em jogo, apresentado em chave duplamente negativa. A primeira negação incide sobre um primeiro "silêncio", enrustido ou impuro. Silêncio que ficaria a meio caminho de sua própria vocação radical, traída por um querer dirigido a seu lado oposto, a palavra. Com a segunda negação, outro silêncio recusado, desdobrando mais uma vez o estatuto do primeiro. Em oposição ao culto da "palavra" - escrita ou falada? - surge o que lhe escapa, a gestualidade corporal, a celebração da pura contingência da experiência ("bater palmas pras performances do acaso"). De um lado a arte, de outro, a vida, o "O alternativo poetas dos anos 70" (Leminski 2012: 70). Porém, a oposição se desdobra, junto ao incontornável paradoxo: bater palmas é acabar com o silêncio.

Logo vemos que onde podemos situar algo da ordem da poesia marginal também podemos situar seu polo oposto, o emblema maior da potencialização do acaso e do silêncio, Stéphane Mallarmé. E, de fato, quando lemos "performance" em um "ensaio/ anseio" de Leminski, já ouvimos falar simultaneamente da forma emblemática da arte experiencial ou antiartística e de modos de experimentação que poderiam ser encontrados na "literatura", esta apresentada como campo de exterioridade plural com relação ao reinado do eu, e que permitiria "performances verbais tão vivas quanto a própria vida" (2012: 61; 64-65).

Epigrafado pelos dois primeiros versos do poema aqui comentado, um amplo levantamento crítico realizado por André Dick (2004) deixa pouca dúvida acerca da presença de Mallarmé no poeta curitibano. Por outro lado, é possível reencontrar o "salto" leminskiano não apenas como internalização e afastamento com relação ao acaso, mas em outros aspectos da demonstração que Mallarmé operou, com alcance máximo, do estatuto paradoxal do silêncio nas artes verbais. Se toda poesia é silêncio que ressoa em sons, a potência do nada só podendo ressoar se realizada em fenômeno verbal, é como se o arauto da dita poesia pura nos dissesse que não há silêncio puro. Dizer este que só pode ser performado, abrindo-se a poesia ao fazer em ato, como de fato fez esse poeta que Marcel Broodthaers conclamou como o "fundador da arte contemporânea" (cf. Rancière 2020). Seria, assim, o caso de dizer que, nesse poema - que, ressalte-se, se apropria da estrutura estrófica do soneto -, opera-se um salto transmedial, que apresenta e amplifica um paradigma moderno do silêncio, em suas tensões materiais-imateriais, auditivas-visuais, em direção a um outro paradigma, espaço-temporal, do silêncio, marcado, como veremos, por uma espécie de salto transdimensional. 
No aspecto métrico, as redondilhas menores que emolduram o poema circunscrevem um concerto de deslizamentos entre a normatividade das redondilhas e transgressões mínimas ora sutis, em versos de seis, quatro e oito sílabas, ora mais radicais, como na ruptura realizada em "apenas um e eu posso deixar o espaço". Quanto aos jogos das rimas e das sonoridades, de "palavras" a "palmas", a rima precisa ser escutada entre os encontros-desencontros do tônico com o átono (em linha com os restos silábicos deixados pela escansão e diferentes possibilidades concomitantes de elisão), sendo perdida de vista quando o "acaso" vem à tona. Mas, em meio a outros afastamentos e aproximações paronomásticos e via assonância, cria-se uma linha de continuidade ou memória justamente quando se trata de "silêncio", "esquecimento" e "tempo". Para perceber isso, não se pode escolher de modo taxativo entre o oral e o falado. A primeira redondilha maior dá forma (in)justamente ao complemento "pras performances do acaso". Curiosamente, é a escolha do falado ("pras") que garante o primado da escrita metrificada. Do mesmo modo que, se a orquestração vigorosa de aliterações ao longo de todo o poema encena por si própria as dobras entre som e silêncio, as repetições de "silêncio", "palavras" e "um" indiciam tanto a profusão da fala quanto um jogo de reagenciamentos dos vocábulos escritos.

Com efeito, a profusão ganha o primeiro plano quando a definição negativa do sujeito cede passo à definição positiva: "sou um rio de palavras/ peço um minuto de silêncios/ pausas valsas calmas penadas/ e um pouco de esquecimento". Porém, entramos não na fala desbragada de um sujeito caudaloso, mas na corrente sonora que marca um deslocamento mais decisivo, do não-ser a um ser que toma corpo em ato, assume o protagonismo no espaço e no tempo, para instaurar o presente de um "pedir". Se Leminski já advertia que "são muitos os silêncios" (2018: 19), o sujeito-rio orquestrará a multiplicidade de uma performance presente-ausente, entre ataques musicais ("valsas) e os vazios das "pausas", ao longo de uma hesitação material-imaterial que ecoa do fantasmático ("(c)almas penadas") à tranquilidade distanciada dos mínimos gestos de escrita ("penadas"). O poema arma, assim, algo como um "teatro de operações," termo militar que designa os campos de ação de guerra, como na "guerra de sentidos" por meio da qual outro poema brilhante do livro (Leminski 2013: 46) mostra-se apto a extrair "consequências" e "baratos" dos intervalos que ecoam em meio a subtrações estratégicas, onde os diferentes "sentidos sensíveis" irritam-se entre si e junto ao "sentido sensato" (Nancy 2001: 170).

Afinal, o "esquecimento" é a condição de possibilidade da memória. Mas, que esquecimento é esse que basta para desdobrar irreversivelmente as passagens do "não sou" ao "sou" e do "peço" à dramatização da impossível coincidência entre os tempos da enunciação e do enunciado, da escrita e da leitura - "apenas um e eu posso deixar o espaço/ e estrelar este teatro/ que se chama tempo"? Por certo, algo familiar à dinâmica de apagamento do acúmulo de eventos que marca a temporalidade da experiência da escuta ou da música, por oposição à plena disponibilidade simultânea dos eventos dispostos espacialmente. Ou o paradoxo de memória e esquecimento que caracteriza o livro (como 
Dick sugere, em um comentário específico ao "Livro" de Mallarmé), a página em branco como "lugar onde/ se faz/ o que já foi feito" (Leminski apud Dick 2004: 74), ecoando o lugar complexo concretista ("A ninguém o passado deve mais/ do que a esses futuristas) ou a "história” como "Lugar absoluto" (Leminski 2018: 368, 65).

Porém, na estrofe final "esquecimento" se faz escutar ao mesmo tempo como ele mesmo ("apenas um esquecimento e poderei") e como a posição do sujeito ("sou apenas um e posso"), lembrando a posição "poeta" que já se definiu como elipse multiplamente desdobrada - "lembrem de mim como de um/ que ouvia a chuva/ com quem assiste missa/ com quem hesita, mestiça/ entre a pressa e a preguiça" (2013: 78). O sujeito se diz "apenas um" e se faz múltiplo, tanto enquanto posição passível de ser ocupada em diferentes embreagens, quanto ao assumir o estatuto que Henri Meschonnic atribui ao sujeito mallarmeano, "simultaneamente o lugar, a operação e o operador" (Meschonnic 1986).

Daí que o sujeito possa simultaneamente ser a "estrela" que protagoniza o espetáculo e a instância que opera, por assim dizer, um "estrelamento" do espaço do poema. Em "O tema astral”, vemos a metáfora mallarmeana do céu estrelado enquanto "A página máxima" traçar uma trajetória comum à estrela e a um desejo de "ir além" que brilha nos “vazios celestiais" (Leminski 2012: 76-80). Se "O céu estrelado é poeta e é poema”, no "poema-constelação", "o observador perturbará a estabilidade daquele um - significado - só, quebrando a tirania do linear" (ibidem). Como o desejo, a estrela é um estar-entre:

A estrela é distância. A esperança.

Espaço que vai entre o desejo e o objeto do desejo.

Entre o relativo e o absoluto.

"Estrelar o teatro", pode, então, ter a ver com uma experiência ativa-passiva impressa na noção freudiana de "sideração", que abre margem para esclarecedoras expansões por certa vertente da psicanálise lacaniana (Didier-Weill 1995). Uma experiência onde a repetição do mesmo é subitamente perturbada pela irrupção do desejo do sujeito que, estando no mesmo lugar, defronta-se repentinamente com uma desestabilização desse lugar, aberto agora a uma "comemoração do tempo originário" e a uma "quarta dimensão", onde o "espaço é gerado pelo tempo" (Didier-Weill 1995: 13 ss.; 155 ss.). Nesse mínimo teatro da página, o sujeito sobe "no raio de uma estrela", ${ }^{3}$ em uma espécie de duplo salto mortal, em direção a um "além" que coincidiria com o apagamento do "apenas um", e simultaneamente virtualiza o próprio espaço do poema, tornando-o palco (im)puro da vertigem do sumir-subir. Afinal, mortal, o salto deixa irreversivelmente o espaço apenas para retornar infinitamente, renunciado pelos círculos da versura (Agamben 2002) na leitura.

Enfim, também está em jogo o que a palavra pode/não pode, tal como no extremo da singeleza que, em Caprichos \& relaxos, se encontra lado a lado com o poema aqui comentado: "minha mãe dizia// - ferve, água!/ - frita, ovo!/ pinga, pia!// e tudo obedecia” (2013: 
39). Poema este que, enquanto tal, pode tudo e não pode nada, tal como esse performativo absoluto materno que vale apenas durante a presentificação do passado de um adulto, mas instaura magicamente toda a cena diante dos olhos do leitor, nos vazios da página. Enfim, o que o sujeito do poema com que iniciamos precisa/pode é esquecer parcialmente que um texto é sempre apenas um texto, assumindo que não pode ou quer deixar totalmente o espaço, mas sim, como diria Valère Novarina, encenar um "pensamento [que] se estrela", um teatro em que tempo e espaço "multiplicam-se" reciprocamente (Novarina 2009: 93). Um teatro que trans-(i)materializa o poema, quadridimensionaliza os paradoxos modernos do silêncio, em um salto transdimensional que, como veremos, potencializa também certos paradoxos (anti)teatrais em outros contextos.

\section{Sob o olhar do teatro: teatralidade, antiteatralidade}

Desde o âmbito etimológico - theatron: "lugar de onde se vê"; theastai: "ver, observar"; theorein: "olhar para", "especular", origem de "teoria" -, o teatro faz pensar o teórico no regime da ação. Já os atritos do registro escópico com o aural (Cavarero 2011), ressoa uma dupla vocação teatral, de um lado, à integração das diferentes artes e registros sensíveis, de outro, em contexto moderno, à produção de dinâmicas de decomposição entre esses parâmetros. Algo que reverbera tensões entre outros polos: "representação"- "apresentação", associado à ambiguidade da "mimese" entre repetição especular e produtividade ou diferimento (Ramos 2015); o regime do jogo, da ficção ou da convenção e o caráter material, concreto e situado da cena; o pacto de recepção tradicional que evidencia o estatuto de jogo de aparências e o estatuto de "crise" próprio ao signo teatral, dada a materialidade do corpo vivo do ator enquanto suporte (Puchner 2002: 6 ss.). Tensões estas que convergem na vocação do teatro à amplificação de dobras próprias à duplicidade intrínseca à enunciação verbal, entre o dizer e o mostrar.

Na porta de entrada que Richard Wagner forneceu à modernidade teatral (idem: 31 58), integração e decomposição já apontam para um amplo leque de possibilidades de fricção entre os parâmetros cênicos. Nos limites da proposta wagneriana de uma integração unificadora entre o visual e o auditivo, de tornar visível a ação invisível da palavra, a tendência integrativa é delimitada pela diretriz de que os dois registros se reforcem um ao outro: "Apenas onde a visão e o escutado se asseguram reciprocamente de sua aparição, o homem verdadeiramente artista se satisfaz" (Wagner apud Damisch 2012: 450). Enquanto isso proporciona uma ampliação das potencialidades dos jogos de mascaramento e desmarcaramento caros à tradição teatral, uma tendência moderna decompositiva irá desdobrar diferentes modos de exploração das decalagens que desestabilizam o nexo naturalizado entre corpo e verdade. Neste último caso, as relações entre o em-cena e o fora-de-cena e o visível e o invisível, podem se desdobrar, para recorrer a termos psicanalíticos, em operações de fricção entre a integridade imaginária ou especular da cena e a demonstração das fissuras que a colocam na iminência de uma irrupção do real, da apresentação sensível da impossibilidade de uma superfície especular íntegra. 
É revelador, nesse sentido, o destaque dado por Jacques Rancière à encenação como uma instância intervalar e "paradoxal, desde o início" que passou de um estatuto "secundário" à condição de "arte" apenas em um contexto moderno (2013: 125). Antes disso, o que está em jogo é a tensão teatral entre entre mythos e opsis, enredo e espetáculo ou materialidade cênica, marcada pela categorização basal fornecida por Aristóteles (2015). Ainda hoje sujeita a uma margem de hesitação teórica (cf. Ramos 2015: 19-67) e tradutológica, a hierarquia aristotélica que prioriza a primeira instância em detrimento da segunda se complexifica diante da posição ambígua atribuída à opsis, categoria ao mesmo tempo "sedutora" e "estrangeira à arte" da tragédia, na visão do filósofo (Lacoue-Labarthe; Nancy 2013: 12). Como ressalta Lacoue-Labarthe, a recusa aristotélica não incide sobre a opsis como um todo, mas apenas sobre a dimensão do espetáculo no sentido daquilo que se oferece plenamente à visão sob o risco de recair em uma relação de "redundância" com a atuação da palavra (idem: 14-25). De modo que a instância intervalar da encenação não cessará de se complexificar também diante da afirmação de Aristóteles de que a tragédia realizaria sua finalidade mesmo na ausência de atores, como pura "mise-en-lecture" (ainda que em voz alta, na antiguidade grega).

Do ponto de vista do teatro do poema, duas entradas se insinuam. De um lado, de acordo com a proposta de Lacoue-Labarthe, uma consideração da encenação, enquanto atualização em ato de uma forma dramática, na ordem da enunciação ou do "proferimento", como algo que "sobreressalta [sobrerelève] da arte: "o teatro implica uma 'cena', mas esta cena - a mise en acte, a enunciação - é sempre anterior à mise em spectacle" (idem: 22-23). Tendo como exemplo maior o "arquiteatro" de Mallarmé, essa dimensão inclui na "pragmática" da enunciação tanto a produção intratextual de modos colaborativos de figuração verbal e "corporal", quanto uma potência de "quebra do espetáculo" no interior da desestabilização do pacto de plena visão passível de ser produzido pelas dobras da "boca" que, como propõe Jean-Luc Nancy, seria o próprio texto (idem: 36 ss.).

De outro lado, quando Rancière aborda, quanto ao caso paradigmático de Maurice Maeterlinck, o desafio de "dar à música das forças obscuras sua aparência sensível no palco", começam a se insinuar outras tensões internas à esfera da encenação, a partir da "divisão no coração" da expressividade intrínseca ao texto (2013: 120 ss.). Com o simbolismo teatral de Maeterlinck, a materialidade cênica "colocaria de lado" a ideia do autor "para situar o princípio de outro regime causal interno ao texto, outra forma de eficácia do discurso, um modo de expressão rompendo com códigos expressivos estabelecidos". Diante disso, o que se pode imaginar em direção ao teatro do poema não se atém à diferença de parâmetros agenciados (no caso teatral, o dito e o implícito, os adereços, a luz, e assim por diante). Para além de intenções de autores individuais ou coletivos, é possível pensar que a expressividade do pensamento projetado e sua atualização performativa se condensariam em uma única instância no campo da poesia, que poderia operar colocando em cena as relações e decalagens entre as duas, desdobrando-se ainda eventualmente em outras instâncias internas. Ou, ainda, que a encenação seria o lugar 
que articula dizeres, operações e os diferentes parâmetros sensíveis-inteligíveis, dando corpo às múltiplas hesitações internas ao ato, abrindo o fazer como colaboração intrínseca às diferentes dimensões enunciativas, numa espécie de inter-fazer cindido e múltiplo.

Nesse sentido, o salto performativo transdimensional realizado por um poema como o de Leminski agenciaria em grau suplementar uma apresentação teatral das tensões, paradoxos e decalagens internas ao ato e às reverberações entre os parâmetros. Assim, explorar o contínuo de possibilidades ativado pela despolarização mallarmeana entre fazer e não-fazer pode conduzir a uma noção do teatro do poema que traz ao primeiro plano o avesso antiteatral e antidramático ativado em reciprocidade com um campo de ativação dramático do poema que vem sendo fortemente explorado, na chave da produção de posições enunciativas e da apropriação de elementos dialógicos e de certa esfera de "ação" (Sussekind 2008; Glenadel 2019). Entre integração e decomposição, entram em cena funcionamentos enunciativos que amplificam o estatuto altamente problemático da materialidade do poema e suas bifurcações materiais-imateriais, possivelmente remetendo a duas séries teóricas e históricas: uma ligada a desdobramentos críticos modernos de uma tendência contrawagneriana, ilustrada por Mallarmé, à "deposição da petrificação figural da possibilidade enunciativa” (Lacoue-Labarthe; Nancy 2013: 26), e outra, representada pela peculiar noção de teatro mobilizada por Michael Fried no contexto das artes dos anos 1960.

\section{A "ameaça" às artes entra em cena}

Nos últimos anos, a noção de antiteatralidade vem galvanizando um campo de estudos pautado por certa noção do teatral dirigida à apreensão de trânsitos entre os campos do teatro, da literatura e das artes visuais, bem como entre as artes modernistas e, na falta de termo mais adequado, "contemporâneas" (cf. Ramos 2015). No centro do debate encontra-se a indicação de um estatuto decisivo do teatral enquanto "ameaça às artes" (Puchner 2002), onde sua dimensão integrativa traz consigo o fantasma da inespecificidade. Martin Puchner é o autor que demonstra de modo mais contundente a reconfiguração de uma longa história de preceitos e preconceitos teóricos contra o teatro no contexto da constituição de uma imagem fundante do modernismo literário europeu. Para o autor, a referência inaugural do campo antiteatral seria o "efeito Richard Wagner", correspondente à conversão do conceito de teatralidade em um "valor" (2002: 9).

No coração dos agenciamentos literários antiteatrais propostos por Mallarmé, James Joyce, Gertrude Stein, W. B Yeats e Samuel Beckett, Puchner identifica um jogo complexo e ambíguo de apropriações e "resistências" que dialoga fortemente com o jogo análogo desencadeado no campo do teatro moderno. Em ambos os casos, o projeto wagneriano de integração da música e do drama, da palavra e da performance funcionou como um contramodelo para a atualização de tendências antiteatrais teóricas, a começar por Friedrich Nietzsche, seguido por autores seminais como Walter Benjamin, Theodor Adorno e, posteriormente, Giorgio Agamben. "O que Nietzsche ataca”, sugere Puchner, "é o que o 
teatro faz com as outras artes", uma "ameaça" às artes, ou, nas palavras do filósofo, uma “"teatocracia”, a "'loucura de acreditar na primazia do teatro, no direito do teatro de protagonizar as artes, de imperar sobre a arte”" (2002: 33 ss.).

Como denominador comum às diferentes atualizações dessa problemática antiteatral estariam a incapacidade do teatro em produzir obras de arte orgânicas, associada à limitação à produção de formas de "mimese não-mediada", dependente dos processos de "personificação" intrínsecos ao recurso à presença do ator e à esfera problemática do gesto. Exemplar, nesse sentido, seria a identificação de uma incapacidade do gesto em se "transformar em um princípio de composição puro e formal", o gesto ocupando precisamente uma posição transversal aos diferentes parâmetros cênicos (idem: 41 ss.) Por outro lado, Puchner situa as novas configurações antiteatrais do drama e do texto literário em relação ao horizonte autonomista de certo modernismo literário na chave de uma aproximação entre a hegemonia do autor e modos de recepção ancorados no modelo da leitura individual e da atenção concentrada. Aqui a possibilidade de "controle" do autor sobre todos os parâmetros da criação iria ao encontro da configuração de um "contrapúblico privado" (idem: 19), em contraste com uma longa história que situava o teatro enquanto campo privilegiado de produção de modelos para a esfera pública (idem: 9-13).

Daí algumas das operações mais marcantes desses teatros da literatura: a apropriação de formas monológicas e dialógicas e de situações cênicas atravessada por desconfigurações radicais das unidades de linearidade, tempo e espaço; a internalização de indicações de palco e didascálias pelo texto literário, em linha com uma explosão do caráter íntegro e ostentivo do palco material; a destruição produtiva das dramatis personae em prol da manipulação de "montagens isoladas e de gestos e poses" (idem: 29).

De modo revelador, esses diferentes aspectos estarão de algum modo contidos na noção de diegese que Puchner retoma de Platão. Trata-se, quando apropriado pela escrita modernista, de um campo de exploração extremamente fértil da "posição desconfortável do teatro entre as artes performativas e miméticas" (2002: 18). Puchner tem mente a ativação de uma "luta" entre a diegese teatral, "a representação indireta, descritiva e narrativa, de objetos, pessoas, espaços e eventos através da linguagem (outrora a cargo de instâncias como o rapsodo e o coro), e a mimese teatral, a apresentação direta de tais objetos, pessoas, falas, espaços e eventos no palco. No entanto, nas "mises-en-lecture" modernistas, representadas fortemente pela forma do "drama de gabinete" (closet drama), passa-se da importação para "o espaço mimético do palco algo que acontece fora dele" a estratégias modernistas introduzidas no "espaço mimético do próprio palco" (2002: 24 ss). Surgem assim potentes dinâmicas de "desmantelamento diegético", que se "sobrepõem ao espaço mimético do palco camadas de descrição", reagenciando a mimese teatral de modo a "interromper e desmembrar qualquer possibilidade de um palco real assim como de um palco imaginário" (idem: 25-27).

Temos, assim, uma noção de "teatro" ancorada no reagenciamento da materialidade do palco em direção a um estatuto desmaterializado, virtual e compósito, bem como 
modos de tensionamento entre algo da ordem da visibilidade mimética e algo da ordem da dizibilidade diegética. Na contramão da desmaterialização radical ou da "neutralização do órgão técnico produtor da música" (Damisch 2012: 393)4 que dava corpo à integração total wagneriana, poderíamos retornar à "guerra de sentidos" de Leminski, avessa tanto à noção de uma materialidade irredutível quanto a à ideia de uma desmaterialização absoluta, vocacionado a habitar um entremeio material-imaterial multiplamente clivado.

Outro decisivo ataque ao teatro informou a intervenção seminal de Michael Fried no contexto do que poderíamos denominar uma virada teatral representada pela encruzilhada (crux) (Foster 1996) em que se instalou historicamente a arte minimalista norte-americana nos anos 1960. Tendo como alvo o que nomeou como a "literalidade" minimalista, ilustrada pelo célebre "What you see is what you see" de Frank Stella, Fried apresentou um diagnóstico hoje sabido como contundentemente acertado, mediante a inversão de seu sinal judicativo. Na origem desse diagnóstico está a eleição, por Clement Greenberg, de um paradigma estritamente visual de determinação do moderno nas artes, pensado enquanto gesto de especificação e depuração de cada meio artístico, tendo a pintura como modelo (Cf., a título de ilustração, Greenberg 2001).

Porém, o que vem ao primeiro plano é uma concepção da fruição da obra localizada no que se pode caracterizar como a esfera essencialista de um modo de presença atemporal. Distinta de um modo de presença situada temporalmente, a "presentness" defendida por Fried (1998) é "contínua e inteira", tendo como efeito o que o autor define algo nebulosamente como uma "perpétua criação de si mesma", em que "a todo momento a obra está ela mesma inteiramente manifesta", a ser experimentada como "um tipo de instantaneidade". O que está sob ataque é, sobretudo, um tipo de teatralidade radicado na dimensão do tempo e da duração:
A preocupação literalista com o tempo - mais precisamente, com a duração da experiência - é, sugiro, paradigmaticamente teatral, como se o teatro confrontasse o espectador e com isso o isolasse, com a falta de termo [endlesness] não só da objetidade [objecthood], mas do tempo; ou como se o sentido a que, no fundo, o teatro se endereça, fosse um sentido de tem- poralidade, de tempo ao mesmo passando e por vir, simultaneamente passando e recuando, como se apreendido em uma perspectiva infinita. (1998: 166-167; realces do autor)

Daí a escansão do ataque em três asserções: "O sucesso, mesmo a sobrevivência, das artes depende progressivamente de sua habilidade em derrotar o teatro"; "A arte degenera ao aproximar-se da condição de teatro"; e, finalmente, "Os conceitos de qualidade e valor" - [...] o conceito de arte em si - são significantes, ou inteiramente significantes, apenas entre as artes individuais (idem: 163-164; realce do autor). 
Mais uma vez, a dimensão integrativa da "teatralidade" é o alvo da rejeição, agora como reação a uma problematização radical da "especificidade" da obra de arte, que põe em xeque tanto o estatuto dos meios e suportes dados, quanto a possibilidade de um controle "finito" da experiência da obra, de uma "perspectiva" unívoca e fechada. Não por acaso, o que Fried leu como "degenerescência" foi revisto, com sinal trocado, no contexto norte-americano como uma virada fenomenológica (Potts 2000: 207-234), em cujo centro encontram-se formas de presença eminentemente relacionais, correspondentes a inscrições espaciais e contextuais do objeto de arte em função das quais o espectador atualiza modos singulares de percepção situada e pública. Para além desse contexto exemplar, poderíamos falar em uma virada teatral transartística que descontrói amplamente um paradigma modernista ancorado na autonomia das artes e na predominância do registro ótico, dando uma outra volta na problematização do paradigma da cena ilusionista clássica compartilhado pela pintura e pelo teatro, fundado na "absorção" do sujeito espectador no quadro da ilusão mediante a manutenção de uma "distância intransponível" (Damisch 2012: 392).

Nesse sentido, enquanto o paradigma clássico da obra de arte havia sido o quadro, passível de ser compreendido como suporte quadrangular que pré-estrutura o lugar do sujeito da experiência artística (Damisch 2012), agora o paradigma passa a ser a fruição multifocal e temporal da escultura (Potts 2000) e, afinal, do teatro. Mesmo sem mencionar outros modos decisivos de ampliação dos limites da teatralidade do palco às ruas, do cubo branco do museu a um campo expandido da performance, outras formas de irritação dos limites entre a objetidade da obra e seu amplo leque de possibilidades de operar um estatuto de articuladora de diferentes espacialidades exigem ampliar esse mesmo enquadramento. Em suma, do paradigma do quadro passaríamos a um paradigma do teatro, porém aberto justamente a regiões instáveis e ambíguas que não cabiam na noção clássica de teatro, sobretudo no que se refere à desestabilização ou virtualização da relação entre o interior e o exterior da cena.

Afinal, onde ficaria o teatro da poesia nesse contexto? Entre as artes, é claro, mas de que modos? No Brasil, trabalhos recentes vêm atentando para uma ampliação das possibilidades intrínsecas a uma esfera transespecífica da enunciação. 0 teatro da poesia aparece aí como espaço de agenciamento do "modo enunciativo", apto a operar dinâmicas de "entrelaçamento de alteridades discursivas" abertas a um "outro" "por vir" (Glenadel 2019), como na "teatralidade resistente, mas insistente operada por Carlito Azevedo", que converteria os processos de figuração "num jogo em que planos descontínuos de sentido se produzem e contradizem num campo relacional contrastivo" (Sussekind 2008: 64).

Ao mesmo tempo, a virada teatral formulada no contexto norte-americano, teria de ser atravessada por uma vocação da poesia a algo da ordem da "produção" ou "variação de contexto" (Zular 2016: s/d.), uma operatividade poética e ficcional que faz do ato não o lugar de inscrição da obra em espaços englobantes dados de antemão, mas um lugar de efetuação variável, pelo texto, de seus próprios espaços englobantes, o que implica 
pensar modos de "produção de limiares" heterogêneos. Algo que traz à tona um outro tipo de consideração da "ontologia do poema", inseparável do horizonte de uma "perda de lastro", da perda de um horizonte fiduciário comum às posições discursivas que articulam os diversos campos do social, que marca, de modo exemplar, os agenciamentos enunciativos das Galáxias de Haroldo de Campos (Provase 2016)..$^{5}$ Daí uma preocupação fundamental: apreender a produtividade de modos poéticos transmediais que operam não na chave da reiteração de uma "inespecificidade" generalizada dos meios artísticos "contemporâneos", mas no registro da produção articulações singulares e complexas entre campos mediais, convenções, tempos e seus reagenciamentos múltiplos.

Nesse sentido, não cessa de ser útil a imagem do teatro mallarmeano da poesia, em cuja origem, a famosa "crise de Tournon", de teor estético-existencial, converge com uma crise com relação ao teatro. Pois a conquista do "teatro do espírito" do Lance de dados remontaria diretamente ao abandono da busca de um absoluto cênico projetado em Igitur, à impossibilidade de realização teatral prática de L'après midi d'un faune e à conversão imprevista deste e de Hérodiade de um projeto para o teatro em um projeto de escrita poética.

Parcialmente e, resposta oblíqua ao horizonte de comunhão essencialista posto por Wagner (Mallarmé 2010: 101-108), o peculiar "teatro" de Mallarmé desenha um modo paradoxal e ambíguo de (i)materialidade, infenso tanto à ideia da "incorporação carnal" da letra, quanto da abertura absoluta ao "sopro imaterial" (Rancière 2011: 58). Um teatro constituído como instância de apropriações parciais da poesia, da música, da dança, do balé e da pantomima e que elevava a graus extremos a tensão teatral congênita em sua potência de encenação da ficção pura e seu caráter irredutivelmente "objetivo", concreto, apto portanto a construir a ficção pura, ela mesma como espaço de desvelamento do seu "mecanismo de constituição", ou espelho em que a linguagem "demonstra a si mesma" (Agostinho 2020). No espaço "sintático-cinético" do Lance de dados (Alferi 2019: 23-24), a teatralização do pensamento-ritmo (Meschonnic 1985) parece interpor entre mythos e opsis o movimento invisível do rhutmos, enfatizada a dimensão do tempo. ${ }^{6}$

Daí um paradoxo extremamente revelador formulado durante a produção de Hérodiade, o de um poema "absolutamente cênico, não possível ao teatro, mas exigindo o teatro" (Mallarmé apud Cabral 2007: 183). Algo que pode esclarecer o interesse oblíquo de certas propostas poéticas brasileiras pós-1970 por esse poeta "fundador da arte contemporânea" mediante uma reintrodução pós-utópica da "heterogeneidade dos signos e das formas" no "espaço das palavras" (Ranciére 2011: 139). Assim, em vizinhança com a dança, ${ }^{7}$ uma noção "Mímica" e apenas muito problematicamente mimética de cena fornece outra imagem decisiva:

A cena não ilustra mais que a ideia, não uma ação efetiva, num hímen (de onde procede o Sonho), vicioso mas sagrado, entre o desejo e a realização, a perpetração e sua lembrança: aqui se adiantando, lá rememorando, no futuro, no passado, sob uma aparência falsa de presente. (Mallarmé 2010: 130) 


\title{
Impuras perspectivas entre poemas
}

\author{
LE BALLET DE L'ÓPERA A RIO
}

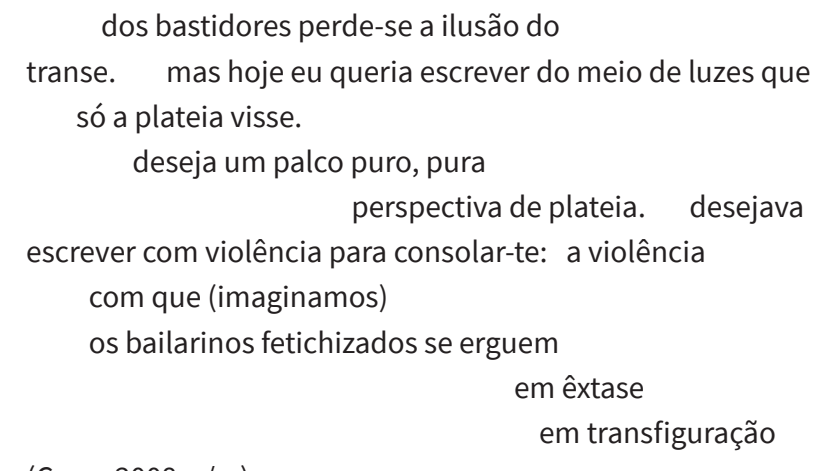

Nesse manuscrito amplamente conhecido de Ana Cristina Cesar, estamos a anos-luz de distância de Hérodiade. Em contraste com a recusa ao toque de uma alteridade que contracena com o símbolo feminino da beleza, a figura enunciadora que orquestra a dança do poema de Cesar pressiona a cena escrita encenando o desejo do toque impossível em um outro fora de cena. Pois, aqui, o que resta dessa suposta pureza é atravessado pela irritação da mediação enunciativa que se interpõe diante de um excesso de corpo e de uma experiência de desancoragem. De todo modo, parecemos estar ainda próximos aos "vazios celestiais" explorados por Leminski, quando o motivo é o "desejo: separação e apartamento do desejado e do desejante, distância, projetos \& obstáculos" (Leminski 2012: 78). Se o tempo do poema de Leminski era conjugado em um presente que decompunha sua suposta integridade nas dobras da encenação, o poema de Cesar desdobra o passado imperfeito projetivo da palavra desejava nas extremidades da página, fazendo da borda do poema o limiar de um salto transdimensional, também, por assim dizer, dado-não-dado.

Como em outro poema de Cesar, esse sim extraído diretamente de Mallarmé, o cerne da ação cênica parece ser a própria ativação desse limiar, irritado desde o início entre a virtualidade irredutível do lado de lá virtual da enunciação e a presença violenta comprimida nas aliterações:

\author{
NADA, ESTA ESPUMA \\ Por afrontamento do desejo \\ insisto na maldade de escrever \\ mas não sei se a deusa sobe à superfície
}


ou apenas me castiga com seus uivos.

Da amurada deste barco

quero tanto os seios da sereia.

(Cesar 2013: 27)

Entre outros comentadores agudos, Viviana Bosi (2015) já destrinchou as estratégias da mimese gráfica de "Le Ballet", situando a hesitação entre "o apelo teatralizado ansioso" e a denotação de "falta e intangibilidade" entre outras figuras de Cesar, extremamente recorrentes, que instalam o poema no limiar da realização "inviável de uma "gana pelo presente" e pela presença. E Roberto Zular (2015) avançou com essa dobra entre o apolíneo e a atualidade cindida do êxtase dionisíaco, desdobrando outras consequências do estatuto desse "ponto de articulação" ou "viragem" que Bosi situa na localização do problema da "perspectiva", que rasga ou torce estrategicamente o corpo do poema, indicando o lugar paradoxal da instância enunciativa, como simultaneamente "visão de fora" e "visão de dentro", palco, plateia e coxia. Entre essas consequências, o prefixo "trans" em "transfiguração" se multiplica, por exemplo, entre "a palavra e a imagem, a materialidade e o símbolo" e a "transformação contínua da própria transformação", aberta pelo lugar tenso de um gesto "quase pornográfico de transparência”, que dá voz à violência crua do jogo de olhar e ser olhado.

Assim sendo, cabe aqui apenas reverberar imaginar uma extensão do "diálogo entre a cultura francesa e a brasileira" que Zular depreende desde o título do poema. ${ }^{8}$ Sugestão esta que poderia reforçar a hipótese de uma encenação poemática do regime de suspensão múltipla desejante do "poder" clivado da palavra poética em dar carne ao desejo de todo texto de não ser texto, aliás formulado expressamente por Cesar em contato com Mallarmé. ${ }^{9}$

Nesse sentido, seria o caso de insistir na decomposição enunciativa, pelo poema, de uma pureza perspectiva, mas também medial e estética-experiencial. Na miragem do "virgem verso" que ressoa oculta, subtraída do título "Nada, esta espuma", poderia vir à tona algo como o jogo de espelhamentos encontrado em alguns estados do poema "Fragmento". Ou seja, entre a "bruta castidade" e a "pureza recusada" (Cesar 2008: s/p), onde a "aventura de recusar a fenda" realiza a recomposição impossível da irreversibilidade experiencial em reversibilidade poética: "percorrendo" "a dúvida a pele/ que refaço". De modo que nesse hímen teatralmente recomposto seria possível ler uma "trans-figuração" do "hímen das artes" de Mallarmé, onde "cada arte, valorizada em sua diferença, inclui seu outro excluindo [...] seu próprio"10 (Illouz 2012: 11). Pois, aqui, integrar significa simultaneamente separar, porém de modo a fazer da abertura do intocado um espaço ambíguo entre experiência e experimentação, entre a reversibilidade do ato poético e a contingência irreversível da experiência.

Assim, seria o caso simplesmente de insistir em uma camada suplementar do limiar paradoxal que situa o lugar da enunciação do poema entre o querer, o poder e o fazer, 
entre sua instalação em uma "pura perspectiva de plateia", ou na absorção do espectador no quadro da ilusão, e a revelação dos "bastidores", ou do esforço violento dos bailarinos sob a elevação ilusionista da graça em movimento. Quando a enunciação articula-desarticula essas duas posições em uma terceira posição intervalar, uma constatação elementar se impõe. A saber, a de que uma forma de diegese hiper-paratópica ${ }^{11}$ ou "soberana" (Agamben 2005), diversa tanto da diegese teatral clássica quanto da internalização modernista da inscrição diegética do fora na cena, estrutura todo o poema, esvaziando e virtualizando toda a ação cênica que corresponderia ao espetáculo apenas imaginado.

Porém, mais precisamente, constata-se que tudo o que resta da cena ausente é o que está impresso no "corpo"12 do poema e que, portanto, a enunciação da impossibilidade do espetáculo imaginado, afinal de contas, realiza o oferecimento de um espetáculo ao leitor espectador. Se o poema encena a dança em coreografia "pictográfica", para utilizar termos de Sussekind (2016), a mimese ${ }^{13}$ se insinua como corpo estranho e ao mesmo tempo endógeno à diegese. Não para realizar o poder de fazer o que se diz, mas para reencenar em grau suplementar o paradoxo que assume o lugar dilacerado de uma cena de escrita radicalmente desmaterializada e desencarnada, mas em cujo corpo material-imaterial se imprime o resto sensível mais pregnante do espetáculo que instaura seu não-acontecimento.

Sendo esse o caso, a ruptura e decomposição da pureza que o poema encena pode ser entrevisto por mais de um ângulo. Se a contribuição do teatro à civilização ocidental seria atingir "a forma acabada da ilusão", como quis Pierre Francastel (Lopes 2017: 19), o que implica absorver o espectador mediante a instituição de uma distância intransponível, o nó encarnado em "puro, pura/ perspectiva de plateia" demonstra muito da questão da "violência”. Onde podemos ler, nas entrelinhas, "desejo, pura, um palco puro", vemos também a perspectiva como ponto cego que articula uma relação eu-tu, que remonta, como mostra Hubert Damisch (2012: 44-63), ao paradigma perspéctico posto pelo Renascimento, onde pintura, arquitetura e teatro guardavam nexos inextrincáveis. Trata-se de um ponto "real", inescritível, que sustenta a cena imaginária ou especular ao estruturar o conjunto das posições da "enunciação". E que, nesse mesmo passo, se situa como ponto cego entre o ponto de vista e o ponto de fuga, enquanto único ponto que o olho não pode ver. Pois se o olho olhasse a si mesmo, se perderia de vista toda a cena, implodindo-se a "estrutura de exclusão" que caracteriza a perspectiva artificial, fundada na configuração do interno como foraclusão, ou recusa internalizadora do fora. ${ }^{14}$

Assim como, em Mallarmé, a ficção é o "espelho" em que a linguagem "demonstra-se a si mesma", Damisch mostra como toda ordem perspectiva clássica comporta uma dupla função de apresentação e demonstração (cf. Damisch 2012: 112-123). Nesse contexto, o que a perspectiva mostra se refrata em uma função de espelho que de-monstra o próprio modo com a cena se enuncia. No poema estudado, contudo, o "ponto real" da perspectiva, pensado em termos lacanianos enquanto "dobradiça" simbólica entre o "real” e o "imaginário", transfigura continuamente as relações entre os registros da lin- 
guagem, da imagem e do excesso pulsional que não cessa de não se escrever entre os dois registros. A "pura perspectiva de plateia" demonstra-se impossível, insinuando, entre distância e contato, a dilaceração consciente implicada no fato de que oferecer uma perspectiva central é impor um modo apresentação que captura o receptor em uma única versão do mundo. Ao mesmo tempo que o regime de transparência pressuposto pela perspectiva clássica cede passo aqui a diferentes modos de irritação da opacidade do meio, replicando, entre a virtualidade da cena e a materialidade ambígua do corpo, uma distorção perspectiva que colapsa, difrata e abre a pureza do sistema.

Assim, seria possível ler aqui que tampouco há meio puro, o que implica consequências éticas e políticas. Quando a gestualidade vem ao primeiro plano no poema comentado, a suspensão teatral interposta entre "o desejo e a realização, a perpetração e sua lembrança" traz à tona a noção do "meio puro" cogitado por Mallarmé em Mímica, cujo comentário por Giorgio Agamben foi bem destacado por Glenadel (2018: 9). Caudatário da linhagem de críticos antiteatrais do gesto (Puchner 2002: 37), Agamben extrai daí uma outra potência do gestual, identificando no estatuto moderno da imagem uma "polaridade antinômica" entre a "reificação e o apagamento do gesto", entre o engessamento de seu estatuto de potência, naturalidade e contingência e um impulso de "conservar intacta a sua dynamis" (Agamben 2005: 57-59). O gesto aparece aí em um lugar intervalar entre o "fazer" e o "agir", ação soberanamente estruturante. O que a dança mostraria seria uma "medialidade pura", o gesto como "a exibição de uma medialidade, o tornar visível um meio como tal". Dado que o gesto "não tem especificamente nada a dizer, porque aquilo que mostra é o ser-na-linguagem do homem como pura medialidade" (ibidem), e que essa abertura negativa do ser na linguagem não pode ser plenamente inscrito como linguagem, o estatuto do gesto seria o de uma abertura ética.

Poderíamos identificar nesse raciocínio um lugar análogo àquele atribuído por Agamben à voz. A voz como intervalo de inclusão-exclusão da phoné no logos, como abertura virtual da medialidade vocal que sustenta a linguagem articulada, o que abriria espaço para uma "enunciação sem enunciado", para um chamado que convoca a uma subjetivação não determinada por via normativa (Dolar 2006: 11). O gesto, o meio e a voz aparecem aqui, portanto, como abertura para um agenciamento por vir. E, contudo, se lembrarmos de uma célebre proposição sobre o estatuto dos meios na arte pós-1960, acessaríamos o meio como "estrutura recursiva - uma estrutura, isto é, alguns dos elementos a partir dos quais serão produzidas regras que geram a estrutura em si” (Krauss 1999: 6), implicando processos de reagenciamento das convenções sedimentadas nos campos das artes. Dito de outro modo, os meios artísticos só gerariam a si próprios na medida em que se apresentam como planos que virtualizam sua própria constituição enquanto espaços de agenciamentos liminares entre atos e convenções, o que certamente abre a opacidade medial ao agenciamento simultâneo de mais de uma linguagem, de uma perspectiva, de uma arte.

Se no poema comentado uma suposta gestualidade pura vem ao primeiro plano, trata-se de gestos que instauram um não-acontecimento que, paradoxalmente, acontece, 
mas que, "abdicando da proa e optando pela popa", como sugere Raul Antelo, incorpora e ultrapassa a hesitação mallarmeana entre o infinito e o nada em direção a um agenciamento da dobra entre o paradoxal acontecer poético e sua inscrição em um horizonte "pós-eventural" (Antelo 1998: 91). Do estatuto "último" do "limite" passa-se ao estatuto "penúltimo" do "limiar", que "busca sair dessa série e começar outra" (ibidem). Se produzir "efeitos de teatralidade" significa agenciar o espaço relacional que, anterior à cena, a possibilita como modo de implicação do outro, Cesar transfigura o "paradoxo" clássico que implica o espectador por meio de sua "neutralização” (Fried 1980: 108-109). E se a antiteatralidade modernista dobrava os limites ambíguos do suporte sobre seu próprio interior, Cesar desdobra a objetidade do poema em teatro paratópico de perspectivações, espaço de encarnações parciais do peso impossível da carne na leveza paradoxal do poema.

Em suma, no poema de Cesar, a impureza plural do meio é demonstrada em cena, atravessada tanto por seus diálogos transtemporais quanto pela distorção paratópica da perspectiva, impressas em uma corporeidade ambígua, onde se imprime a pressão excessiva de um presente que contamina a materialidade que sustenta a enunciação. Ensaiada na dobra entre as décadas de 60 e 70, essa poesia rompe a ilusão de pureza por dentro e por fora, orquestrando a negatividade suspensa da ética por vir como encenação transespecífica, transtemporal e transdimensional. Um teatro que prefigura outras transfigurações a "estrelar" futuros espaços-tempos.

\section{O palco, o espelho, o sangue}

Encarnação parcial e múltipla de um estatuto liminar do teatral, o balé paratópico de Cesar ocupa um lugar revelador no interior de uma poética da desancoragem. Se o poema poderia ser associado a um flerte com uma "escrita construtiva" identificado por Sussekind (2016: 34), quando o branco da página vem ao primeiro plano dessa poesia, o que vem à tona não é a fusão da terra e do céu na infinitude de um "horizonte unânime", como no Lance de Mallarmé (2013: 89), mas uma multiplicidade de horizontes em deslizamento simultâneo. É o que se nota na fricção entre o transitório por excelência e um regime do "sempre", no dístico que protagoniza todo o espaço do poema "recuperação da adolescência": "é sempre mais difícil/ ancorar um navio no espaço" (Cesar 2013: 17).

Quatro décadas depois, outro teatro transversal nos dá uma imagem das potências políticas e transtemporais que podem aflorar entre a lógica transversal e paratópica da enunciação e a imanência irredutível e mesmo desolada ${ }^{14}$ das condições que sustentam o horizonte enunciativo atual. "O coração dos homens", de Veronica Stigger (2016), encena o assunto impresso no título do livro Sul, referente, por um lado, a um histórico de violência social tingido de conservadorismo moralista, relacionado ao estado do Rio Grande do Sul, onde nasceu a autora. E, por outro, ao baixo materialismo ocultado pela civilidade burguesa, mobilizado pelo tema central da primeira menstruação, acontecimento irreversível que divide as águas da subjetivação feminiza, turvando de impureza um suposto estado inicial "puro". 
Para encenar a demonstração desse ponto cego onde convergem o real do corpo e o real inescritível da violência social, de que faz parte a invisibilização dos sujeitos femininos, Stigger aciona uma vocação teatral à decomposição espectral daquilo que se mostra não se mostrando em cena, por meio de uma cenografia transversal. Desenvolve uma textualidade próxima à do conto, porém estruturada a partir de convenções do campo da poesia, para dar palco a uma voz adulta que reconstrói a participação do sujeito em uma peça de teatro durante a infância, durante a qual ocorre sua primeira menstruação.

Na primeira e mais extensa das três seções que compõem a primeira parte do texto, percebe-se que a estruturação em versos enfatiza a irregularidade da versificação, dando corpo ao que não cabe nas convenções do texto poético, na autonomia da poesia em relação ao teatro e a prosa e, valorizando o vocabulário popular, nas "regras" da mulher, na delimitação temporal do período da menstruação. Quando escutamos a reenunciação da recitação paródica de preceitos cristãos de pureza pelas crianças envolvidas com a peça de teatro infantil, encontramos um fluxo sanguíneo e simbólico que atravessa todo o texto:

"Quando uma mulher tiver um fluxo de sangue de diversos

[dias

fora do tempo das suas regras, ou se as suas regras se

[prolongarem,

estará no mesmo estado de impureza em que esteve

[durante o tempo das suas regras (2016: 75)

A ameaça de contaminar a tudo e a todos preconizada pelo preceituário religioso vai ao encontro da figura do espelho, fundamental à construção da operação decisiva do texto, a da localização da voz atrás do espelho. Tudo parte da rememoração pela voz adulta de sua atuação na peça infantil no papel de "Espelho":

Foi aí que menstruei.

Era minha primeira vez.

Ninguém notou.

Eu ficava atrás do espelho.

Ninguém me via.

Só me ouviam (e olhe lá).

Eu também não via ninguém.

Meu horizonte era o verso do espelho:

uma grande moldura de madeira mofada.

[...] 
Todos viam o espelho, e o espelho refletia a todos menos a mim.

(idem: 65-66)

Com efeito, todo o texto irá desdobrar uma dinâmica de espelhamentos, internamente sabotado por meio de distorções e refrações. Primeiro, por meio de divisões polares, simetrias, e duplicidades, a começar pelos atores infantis e "monoglotas" que deviam dar o texto em inglês, fazendo a peça descambar rumo ao obsceno imprevisto: "Ao colocar os anões para dormir, ela os cobria com merda/ em vez de lençóis" (sheets/ shit). Segundo, no que toca às relações entre a circunscrição narrativa da cena teatral infantil e o espaço retrospectivo de rememoração dos bastidores problemáticos da peça, que revela a experiência interior da menina que busca esconder a primeira menstruação dos demais presentes. Sendo que um terceiro plano, o mais contundente, replica precisamente o lugar paratópico da voz, desdobrando os espelhamentos internos à cena narrada e ao espaço da rememoração por meio da organização do texto em duas partes aparentemente simétricas: "O coração dos homens" e "A verdade sobre o coração dos homens", ambas subdivididas em três seções, a primeira delas iniciando pela mesma sequência de versos.

É assim que, por trás da própria voz por trás do espelho, esta superfície reflexiva vê subvertida sua função de estabelecimento especular da identidade do sujeito, algo que se desdobrará nos mais diversos planos da cenografia dessa enunciação. No teatro de Stigger, toda a problemática especular da perspectiva clássica, pautada pela exclusão soberana de tudo que excede o quadro e pelo ocultamento do ponto de origem que estabelece a posição que implicará o espectador à distância, é agenciada pelo avesso. A voz ocupa ambiguamente o "ponto real", ou o ponto de "origem" da enunciação, a "charneira" simbólica entre o imaginário e o real, modulando ambiguamente o que é interno e o que externo ao enquadramento cênico materializado pela peça infantil. O espelho intracênico reflete a tudo e a todos exceto a protagonista rememorada, assim como a posição paratópica da voz orquestra todo o jogo de remissões entre a peça, a rememoração e a maquinaria do dispositivo do livro.

E isso graças a um salto transmaterial que eleva o jogo de reflexos a um grau suplementar: o livro é confeccionado de tal modo que, para se ter acesso à segunda parte do texto, que supostamente revela "A verdade sobre o coração dos homens", é preciso literalmente cortar as páginas, mantidas estrategicamente seladas. De fato, o que lemos na segunda parte seria a voz da autora adulta, que revela todas as distorções e falsidades por meio das quais teria adaptado seu material biográfico para construir o texto. Porém, enquanto supostamente tocamos a verdade íntima da autora, logo somos instados a quebrar o que restaria de uma "suspension of disbelief", quando a voz diz, como se nada, "Faço parte de uma família de mitômanos". Interrupção esta por sua vez replicada em 
outros planos, a começar pelo contraste entre a dinâmica do fluxo menstrual, que uma vez originado não para de protagonizar toda a cena, e outra revelação parcial: "Hoje não sonho nada de interessante./ E não menstruo mais./ Porque também não ovulo" (idem: 88). Daí um segundo nível de conotação ativado pela cenografia teatral que sobrepõe uma prosa altamente oral e o registro da poesia: demonstra-se as brechas no ocultamento do fluxo abjeto em seus tensionamento com uma arquitetura da concentração.

Com isso, o antiespelho ou contraespelho que, ao invés de revelar a verdadeira identidade, faz da voz uma superfície de reflexões distorcidas, é desdobrado, no nível da organização das partes do texto. Opera como a dobradiça que articula duas superfícies supostamente simétricas, uma imaginária, outra realista, porém, na verdade cindidas assimetricamente, de modo que a segunda, que revela o que seria estruturalmente excluído da primeira, na verdade constitui apenas mais uma superfície especular opaca. De modo que essa operação de decomposição da identificação entre sujeito empírico e figura enunciadora convoca o espectador a ocupar o mesmo lugar paratópico instituído pela voz. Pois, ao implicá-lo no ato de rasgar a pureza imaculada do livro para ter acesso à verdade do acontecimento menstrual supostamente original, o texto desloca o leitor em relação tanto a uma absorção plena no pacto ilusionista quanto a uma distância intransponível que autorizaria um sobrevoo apto a sondar a verdade total do que lê.

Com isso, o leitor se vê implicado na necesside de modular os reflexos de uma verdade equívoca e parcialmente ancorada, o que traz à tona outra camada de encenação do paradoxal e equívoco acontecer poemático. Pois o que se interrompe na borda entre o texto e o livro de Stigger é não apenas o jogo especular, mas também o caráter fundamentalmente reversível da experiência de leitura, maximizado pela circularidade da versura, mas sem deixar de ressoar, pelo avesso, a "lei de reversibilidade" que constitui princípio basal do pacto teatral ilusionista. ${ }^{16}$

Afinal, a primeira menstruação, acontecimento irreversível e interditado ao olhar, extravasa a cena e passa a ocupar o ponto cego anterior-posterior da organização material do livro. Assim, o jogo teatral entre sinceridade e fingimento é atravessado por uma demonstração de múltiplos planos de cisão que tornam infinitamente complexo o estatuto dos corpos falantes em suas embreagens móveis da verdade. De modo que as distorções que fissuram a linguagem a partir de um estado infantil da palavra mostram-se aptas a agenciar, com humor, a violência que circula do enquadramento do corpo à partição entre os gêneros e à conservação cínica de uma moral sem lastro. Quando a violência é rotinizada como onipresente, cuja emergência real multiforme e insituável costuma ser reduzida ao apontamento de bodes expiatórios condenados à invisibilidade, surgem vozes que demonstram a impossibilidade de gritar, como fazem os delatores pseudopoliglotas do paradeiro da Branca de Neve, "She is there!".

Assim, do salto mortal irreversível-reversível de Leminski, às múltiplas camadas do hímen reversível transfigurado de Ana Cristina Cesar, chegamos a um teatro da demonstração de uma invisibilidade social que irrompe em fluxo reversível-irreversível. Quando 
a reversibilidade utopicamente total das condições materiais já não encontra nem o horizonte da revolução da arte como revolução da vida que foi decomposto por Leminski, nem a pressão de um presente onde os excessos violentos do corpo possam "consolar" a perda de um horizonte comum, como em Cesar, cabe ainda decompor a saturação hiperdesmaterializada da palavra e a materialidade irredutível das condições de troca entre os sujeitos. Cabe, enfim, nas mínimas cenas de um teatro transdimensional, a possibilidade de atravessar em chave transespecífica e transtemporal o que os diferentes campos de convenções oferecem como potência de novos reagenciamentos, novas formas de "estrelamento" ou sideração do espaço do poema.

\section{NOTAS}

* André Goldfeder é bacharel em Ciências Sociais pela Faculdade de Filosofia, Letras e Ciências Humanas da Universidade de São Paulo (FFLCH/ USP) - Brasil) e mestre e doutor em Teoria Literária e Literatura Comparada pela mesma instituição. Seus principais campos de atuação são: Poesia moderna e contemporânea; Literatura Comparada (artes visuais e teatro); Psicanálise e Teoria social. Atualmente é pós-doutorando junto ao Departamento de Teoria e História Literária da Universidade Estadual de Campinas (Unicamp - Brasil).

${ }^{1}$ Este trabalho foi realizado com apoio da Fundação de Amparo à Pesquisa do Estado de São Paulo (FAPESP) processo $n^{\circ} 2019 / 13591-3$.

${ }^{2}$ O presente comentário ao poema de Leminski é amplamente devedor do ensaio de Zular e Lucas, bem como de trabalho coletivo que aborda o contexto aqui estudado com foco na questão da historicidade (Goldfeder; Lucas; Provase; Zular 2019).

${ }^{3}$ Além de ter deixado em vida uma filha chamada Estrela, Leminski deixou uma letra de canção que foi musicada, após a morte do poeta, por José Miguel Wisnik, este que incluiu magistralmente um verso final suplementar, desdobrando a topologia paradoxal do dêitico "aqui" na imanência-transcendência da canção, que passa também a consumar ambiguamente a entrada mínimo-máxima de Leminski na plêiade dos poetas brasileiros e nas paradas de sucesso da canção popular: "Subir/ No raio de uma estrela/ Subir até/ Sumir/ Subir até sumir/ No brilho puro/ Subir mais/ Subir além/ Além de toda a treva/ De toda a dor/ Além de toda a treva/ De toda a dor/ Deste mundo/ [Pra chegar até aqui] (Wisnik 1992).

${ }^{4}$ Tendência na qual convergiriam todos os parâmetros dessa teatralidade total - o ocultamento da orquestra, a "melodia infinita" e o cromatismo musical, a dissolução ótica do solo e do fundo, que produzem um efeito de "longinquidade infinita”, e assim por diante. 
${ }^{5}$ Sobre os aspectos sociopolíticos em jogo no caso brasileiro,ver Goldfeder; Lucas; Provase; Zular 2019.

${ }^{6}$ Ênfase postas por autores como Bertrand Marchal e Meschonnic nas nuances que renovam a imagem de Mallarmé presentes nas notas para um projeto de doutorado abandonado pelo poeta, conhecidas como "Notes sur le langage". Cf. Agostinho 2020.

${ }^{7}$ Cf. o comentário de Puchner à "ecfráse descritiva" da dança de Hérodiade, excluída das versões mais estabelecidas do poema por Mallarmé (Puchner 2002: 63-64).

${ }^{8} \mathrm{O}$ autor tem em mente a informação da passagem do Ballet da Ópera de Paris pelo Teatro Municipal do Rio de Janeiro 1974 (cf; 2015: 84) - vale ressaltar, ano da publicação das traduções e estudos mallarmeanos publicada pelos poetas concretos sob o título Mallarmé, sucedida em dois anos pela publicação de "Nada, esta espuma".

${ }^{9}$ Comentando o "Salut" de Mallarmé, Cesar indaga: "Quais são seus poderes? Será que a linguagem pode expressar alguma coisa a respeito do mundo e do meu próprio ser? Será que o verso é virgem? Ou será o nada? Ou meramente espuma?” (1998: 414).

10 "Como o fauno deseja todas as ninfas, L’Après-midi d'un Faune reivindica todas as artes; sob condição, entretanto, de que esse ‘hímen' das artes, à imagem do ‘hímen desejado' do fauno e das ninfas, una as artes entre si, preservando a 'virgindade de cada uma', a figura do hímen representando assim "um novo paradigma das relações inter-artísticas, implicitamente oposta à fórmula wagneriana da 'arte total’” (Illouz 2012: 4).

${ }^{11}$ Dominique Maingueneau define como "paratópico" o lugar "impossível” ou intervalar a partir do qual a enunciação estrutura as articulações entre o interior do espaço do texto e sua exterioridade, ou seja, o lugar interior-exterior do ato que circunscreve o dentro no mesmo passo que legitima o seu fora (cf. Maingueneau 2012: 87 ss.)

12 "Olho muito tempo o corpo de um poema/ até perder de vista o que não seja corpo/ e sentir separado dentre os dentes/ um filete de sangue/ nas gengivas" (Cesar 2013: 19).

${ }^{13}$ Questão esta diretamente abordada em "Mímesis", outro manuscrito da "pasta rosa", onde a posição deslocada do "malabarista" dá corpo precisamente às equivocações próprias ao ato de "imitar" algo da ordem dos limiares entre desejo e realização, anterioridade e atualidade do ato de escrita.

${ }^{14}$ Essa maquinaria simbólica seria demonstrada pelo famoso "protótipo" concebido por Fillipo Brunelleschi, tal como Damisch o caracteriza. Trata-se de um pequeno painel, uma "tavoletta", onde o arquiteto representou a visão do Batistério da Piazza della Signoria de Florença obtida a partir da escadaria da Catedral. Em contraste com a paisagem arquitetônica, a visão do céu e da atmosfera não foi pintada, mas deveria ser refletida na superfície de prata polida que o arquiteto instalou acima da representação do edifício. Após pintar o edifício, o arquiteto fez um furo no painel e determinou que o observador deveria girar o pequeno quadro ao contrário, para vê-lo refletido, através do furo, em um espelho a ser disposto diante da face pintada (cf. Damisch 2012: 112-123; 134-162).

${ }^{15}$ Como se vê em "2035", texto que abre Sul.

16 "No teatro, a lei garante a reversibilidade de espaço e evento. Assim, ele se opõe a qualquer ato em que o sujeito é mutilado ou executado. [...] Atos como esses rompem o contrato tácito entre espectador e teatro, que garante que o que se testemunha é apenas representação, inscrita em um tempo e espaço diferente do cotidiano, em que a marcha temporal progressiva é suspensa e portanto reversível, um ato no qual o ator reserva a possibilidade de retornar ao ponto de partida" (Féral 2002: 104). 


\section{BIBLIOGRAFIA}

Agamben, Giorgio (2005), "Bataille e o paradoxo da soberania", tradução de Nilcéia Valdati. Outra Travessia, 5, p. 91-94.

-- (2002), “O Fim do Poema”, Cacto, n. 1, São Paulo, Edições Alpharrábio.

-- (2015), "Notas sobre o gesto", Meios sem fim. Notas sobre a política, tradução de Davi Pessoa Carneiro, Belo Horizonte, Autêntica.

Agostinho, Larissa (2020), A linguagem se refletindo. Introdução à poética de Mallarmé, São Paulo, Annablume.

Alferi, Pierre (2019), De um teatro de papel, São Paulo, Luna Parque.

Aristóteles (2015), Poética, tradução de Paulo Pinheiro, São Paulo, Editora 34.

Aleixo, Ricardo (2004), "No corpo da voz: a poesia-música de Paulo Leminski”, in Dick, A./ Calixto, F., A linha que nunca termina: pensando Paulo Leminski, Rio de Janeiro, Lamparina.

Bosi, Viviana (2015), "Ana Cristina Cesar: ‘Não, a poesia não pode esperar'”, in Faleiros, A./ Zular, R./ Bosi, V. (orgs.), Sereia de papel. Visões de Ana Cristina Cesar, Rio de Janeiro, Eduerj.

Cavarero, Adriana (2011), Vozes plurais: filosofia da expressão vocal, Belo Horizonte, UFMG.

Cabral, Maria de Jesus (2007), Mallarmé hors frontières. Des défis de l'EFuvre au filon symbolique du premier théâtre maeterlinckien, Amsterdam/ Nova York, Rodopi.

Cesar, Ana Cristina (1998), Crítica e tradução, São Paulo, Ática.

-- (2008), Antigos e soltos - poemas da pasta rosa, organização de Viviana Bosi, São Paulo, Instituto Moreira Salles.

-- (2013), Poética, São Paulo, Companhia das Letras.

Damisch, Hubert (2012), L'origine de la perspective, Paris: Flammarion.

Dick, A. (2004), "Paulo Leminski: depois do acaso", in Dick, A. / Calixto, F., A linha que nunca termina: pensando Paulo Leminski, Rio de Janeiro, Lamparina.

Didier-Weill, Alain (1995), Les Trois Temps de la loi. Le commandement sidérant, l'injonction du surmoi et l'invocation musicale, Paris, Éditions du Seuil.

Dolar, Mladen (2006), A Voice And Nothing More, Cambridge/ Londres, The MIT Press, 2006,

Féral, Josette (2002),"Theatricality: the specificity of theatrical language”, Substance n. 98/99, v. 31, p. 94-108.

Foster, Hal (1996), "The return of the real", in The return of the real: the avant-garde at the end of the century, Cambridge, MIT Press, 1996.

Fried, Michael (1980), Absorption and theatricality - painting and beholder in the age of Diderot, Los Angeles, University of California Press.

-- (1998), "Art and objecthood", in Art and Objecthood: essays and reviews. Chicago, University of Chicago Press. 
Glenadel, Paula (2019), "Mínimos teatros: poesia contemporânea e ética”, Outras travessias, v. 1, p. 6-16.

Goldfeder, A./ Lucas, F. R./ Provase, L./ Zular, R. (2019), "Pour une autre historicité : la poésie brésilienne à partir des années 1970”, Brésil(s) - Sciences Humaines et Sociales, n. 15, p. 1-25.

Greenberg, Clement (2001), "Pintura modernista”, in Ferreira, G./ Cotrim, C. (orgs.), Clement Greenberg e o debate crítico, Rio de Janeiro, Jorge Zahar.

Illouz, Jean-Nicolas (2012), “L'Après-midi d'un faune et l'interprétation des arts: Mallarmé, Manet, Debussy, Gauguin, Nijinski". Littérature n.168, p. 3-20.

Krauss, Rosalind (1999), A voyage on the North Sea: art in the age of the post-medium condition, Londres, Thames \& Hudson.

Lacoue-Labarthe, Philippe (2016), Música ficta (figuras de Wagner), tradução de Eduardo Jorge de Oliveira e Marcelo Jacques de Moraes, Rio de Janeiro, Relicário.

Lacoue-Labarthe, P./ Nancy, J. L (2013), Scène, Paris, Christian Bourgois.

Leminski, Paulo (2012), Ensaios e anseios crípticos, Campinas, Editora da Unicamp.

-- (2013), Toda poesia, São Paulo, Companhia das Letras.

Lopes, Angela Leite (2017), Traduzindo Novarina: Cena, pintura e pensamento, Rio de Janeiro, 7 Letras.

Maingueneau, Dominique (2012), Discurso Literário, São Paulo, Contexto.

Mallarmé, Stéphane (2010), Divagações, tradução de Fernando Scheibe, Florianópolis, Editora da UFSC.

-- (2012), Um lance de dados, Introdução, organização e tradução de Álvaro Faleiros. São Paulo, Ateliê Editorial.

Marchal, Bertrand (1988), La religion de Mallarmé. Poesie, mythologie et réligion, Paris, José Corti.

Meschonnic, Henri (1985), "Mallarmé au-delà du silence”, in Mallarmé, S., Écrits sur le livre. (Choix de textes), Pari, Éditions de l'Éclat.

Nancy, Jean-Luc (2001), Les muses, Paris, Éditions Galilée.

Novarina, Valère (2009), Diante da palavra, Rio de Janeiro, 7 Letras.

Potts, Alex (2000), The sculptural imagination: figurative, modern, minimalist, New Haven/ Londres, Yale University Press.

Puchner, Martin, (2002), Stage Fright: Modernism, Anti-theatricality \& Drama. Baltimore/ Londres, The Johns Hopkins University Press.

Provase, Lucius (2016), Lastro, rastro e historicidades distorcidas: uma leitura dos anos 70 a partir de Galáxias. Tese de Doutorado apresentada ao Departmento de Teoria Literária e Literatura Comparada - FFLCH/USP.

Ramos, Luiz Fernando (2015), Mimesis performativa: a margem de invenção possível, São Paulo, Annablume.

Rancière, Jacques (2011), Mallarmé: the politics of the siren, tradução de Steven Corcoran. Londres/Nova York, Continuum, 
-- (2013), Aisthesis. Scenes from the Aesthetic Regime of Art, tradução de Zakir Paul, Londres/ Nova York, Verso.

-- (2020), O espaço das palavras: de Mallarmé a Broodthaers, tradução de Marcela Vieira e Eduardo Jorge de Oliveira, Belo Horizonte, Relicário.

Siscar, Marcos (2010), "A cisma da poesia brasileira", in Poesia e crise, São Paulo, Editora da Unicamp.

Stigger, Veronica (2016), Sul, São Paulo, Editora 34.

Sussekind, Flora (2008), "A imagem em estações - Observações sobre 'Margens', de Carlito Azevedo", in Alves, I. (org), Subjetividades em devir, Rio de Janeiro, 7Letras.

-- (2016), Até segunda ordem não me risque nada. Os cadernos, rascunhos e a poesia-emvozes de Ana Cristina Cesar, Rio de Janeiro, 7 Letras.

Wisnik, José Miguel (1992), José Miguel Wisnik, Camerati.

Zular, Roberto (2015), "Sereia de papel (algumas anotações sobre a escrita e a voz em Ana Cristina Cesar), in Faleiros, A./ Zular, R./ Bosi, V. (orgs.), Sereia de papel, op. cit.

-- (sem data), "Ficção como variação de contexto", disponível em: www.academia.edu/ 39149593/Ficção_como_variação_de_contexto.

Zular, R./ Lucas, F. R. (2016), "Ecos desencontrários de Leminski”, in Malufe, A. C. e Junqueira, M. A. (orgs.), Poesia entre lugares, Sao Paulo, Dobradura, v. 1, p. 48-88. 